\title{
Valuation of Subject Identity by Indirect Personality Profiling (V0) in the System for Analysis of Validity in Evaluation (SAVE).
}

DOI: $10.46932 / \mathrm{sfjdv2n2-207}$

Received in: March 1st, 2021

Accepted in: May 30th, 2021

\author{
María José Garrido Antón \\ Guardia Civil, Madrid, Spain. \\ Email: mjganton@yahoo.es
}

\section{IDENTITY ASSESSMENT}

In SAVE (López, et al, 2018), and although there are other potential factors (intelligence, bonding), the Valuation of Identity or V0 begins with indirect personality profiling, a technique that we consider most useful in Validity Analysis. It starts from a simple premise; by observing a person's behavior we can infer personality traits, without the need for a psychometric tool designed for that purpose (classical or direct assessment).

\section{PERSONALITY AND INDIRECT PROFILING}

One of the great concerns throughout the history of psychology is to try to understand why an individual behaves the way he does. In an attempt to answer this question, a multitude of personality models has been developed from different approaches such as the psychodynamic, medical, or biological. Within the latter, the PEN model (Psychoticism (P), Extraversion (E) and Neuroticism (N)) (Eysenck, 1970) stands out for its simplicity, parsimony, and the number of hypotheses that have been contrasted since the first formulation of the model. For these reasons, it has been the model chosen in the police context to be able to develop indirect personality profiling (González and López, 2016).

Occasionally, situations arise, in the framework of police investigations, where it is necessary to know in the shortest possible time, the personality of a specific subject in order to design an approach strategy, depending on the objectives of the investigation, as successful as possible. An example of this could be a criminal situation with hostages or the interrogation of a detained person in the investigation of a missing person (González, Sotoca, and Garrido, 2015). In this sense, Gosling, Craik, Martin, and Pryor, already in 2005 suggested how individuals tend to select and create their social and physical environment to adjust and reinforce their dispositions, preferences, attitudes, and lifestyles, thus determining how the personality characteristics of people are reflected in their physical and personal spaces. Likewise, Brunswick (1956), approaches this approach through the well-known Lens Model, through which he explains how individuals select and create their own social environment, activities, hobbies, which reinforce their own dispositions, preferences, and attitudes (behavioral indicators), as well 
as those that are deducted from the physical environments (observable indicators). It is worth noting how other research already relates the personality traits of the PEN model to the lexicon used, musical preferences (Rentfrow \& Gosling, 2003), taste for different types of food, sports, use of social networks (Qiu, Lin, Ramsayan, \& Yang, 2012) or tattoo ownership (Lopez, Garcia, Gonzalez, \& Sanchez Buró, 2017).

Along these lines, it is important to determine which elements may reflect such personality constructs, i.e., which indicators can be observed in the natural context of the observed person in order to be able to make inferences with a certain degree of probability about the personality and further about the future behavior of the individual based on these traits.

For the purposes of criminal investigation, it is assumed that personality is composed of a set of temperamental, intellectual, and motivational traits of the person, which makes an individual behave in a certain way in different situations, and that this behavior is identified for him/herself and for others. The methodology presented in this paper avoids the limitations that arise when trying to assess personality through standardized questionnaires from which a series of direct scores are usually obtained. It is at this point that the problems or limitations of deliberate distortion or social desirability of the person being evaluated emerge, that is, the natural tendency, or sometimes intentional, to respond to items that measure personality in response to social pressures or other variables that make one want to show the best or most favorable image for others.

The procedure of indirect personality profiling is understood as that methodology that makes it possible to infer the personality traits of an individual without him feeling observed and without his explicit collaboration, recording in the most rigorous way possible the specific observational and behavioral indicators that saturate in each trait, avoiding in this sense, the limitations mentioned and generating a personality profile of the person that will be widely useful for the development of policy research in different ways. There is currently a whole path of research and development to develop reliable and scientifically proven protocols that can be used by police forces to apply indirect profiling as an aid method to extract indirect information through human sources (Halty, González and Sotoca, 2017).

\section{CONCLUSIONS}

There are, therefore, several scenarios where Valuation of Identity using indirect profiling (V0) is used as a technique to support the police investigation when it comes to knowing the personality of individuals in order to design approach strategies, with the intention of improving the results in the other SAVE phases, both in the interview (V1 and V2) and in the context investigation (V3).

Keywords: Behavior analysis, psychoticism, extroversion, neuroticism, indirect personality profiling. 


\section{REFERENCES}

Eysenck, H. J. (1970). The structure of personality (Trans. M.D. Bordas). Biological foundations of personality, (pp. 45-79). Barcelona: Fontanella (Original 1967).

González, J. L, Sotoca, A., and Garrido, M. J. (2015). Profiling in criminal investigation. In González, J. L and Gimenez-Salinas, A. First edition. Criminal investigation: principles, techniques and applications (pp 211-224). Madrid, Spain. LID editorial.

González, J. L. and López, R. (2016). Personality and Behavior: indirect personality profiling. In R. M., López, F. Gordillo, and M. Grau, (Coord.). Handbook of nonverbal behavior analysis: beyond communication. (pp. 1-37). Madrid: Pirámide.

Gosling, S. D, Craik, K. H, Martin, N. R, and Pryor, M. R (2005). The personal living space cue inventory: an analysis and evaluation. Envioronment and Behavior, 37, 683-705.

Halty, L., González, J.L., and Sotoca, A. (2017). ENCUIST model application to criminal profiling, Yearbook of Legal Psychology.

López, R. M. , Garcia, A., González, P, and Sanchez-Buró, A. (2017). Indirect personality profiling through tattoos. A cross-cultural study. International congress of legal and forensic psychology. Seville (Spain).

López, R. M., Domínguez-Muñoz, A., Grau, M., Juárez, A., Jiménez, J., \& Garrido, M. J. (2018). SAVE metaprotocol for behavior analysis. An integrative proposal. In E. Arias, J. Sanmarco, \& X. Camplá (Eds.), XI International Congress of Legal and Forensic Psychology. (pp. 528-541). Granada: Spanish Society of Legal and Forensic Psychology.

Qiu, Q. , Lin, H., Ramsay, J. \& Yang, F. (2012). You are what you tweet. Personality expression and perception on twitter. Journal of Research in Personality, 6(6), 710-718.

Rentfrow, P. J. ,\& Gosling, S. D. (2003). The do re mi's of everybody life: The structure and personality correlates of music preferents. Journal of Personality and Social Psychology, 84, 1236-1256. 